\title{
IIMII:CONF
}

\section{Organizational Adaptation from Government to Governance (Developing Paper)}

\author{
William Nti Marfo \\ Estonia Business School, Tallin, Estonia \\ Supervisor: Prof Meelis Kitsing
}

\begin{abstract}
The traditional city management's long-established practices are being challenged, which has prompted many cities to adapt from government to governance. Consequently, the role and purpose of the city authorities are reshaped to conform to contemporary city management. This signifies the shift from the city government's central leadership role to a more enabling partnership involving various actors. The challenge now is how the local authorities shift from the top-down government model to collaborative governance, which encourages partnership between private-public and non-governmental agencies. Currently, the business improvement district's (BIDs) has become an innovative city management model and expanding to many cities due to the traditional city government inability to tackling urban challenges. These challenges are due to differences in priorities, objectives, and strategies between different segments of the urban government, or what is called "governance gaps" caused by organizational insufficiency and lack of inter-organizational coordination. The study aims to understand the business investment zone (BIZ) policy in Amsterdam metropolis to understand why the policy was adopted, how this could be improved and implemented to bridge the gap between the traditional bureaucratic city management and the new collaborative governance. This study examines the BIZ policy's policy networks within the Amsterdam Metropolis and how these could be enhanced to boost network performance and collaborative governance in the Randstad region. The empirical analysis points to the preliminary conclusion that network structure does matter for the organizing capacities and the policy networks' performances. This revelation is significant since the knowledge and experiences outlined in this study are likely to be relevant and applicable to other sectors, well beyond those studied. How can the government's organizational adaptation to the governance of the traditional city management system be improved through the policy and governance networks of the business investment zone (BIZ) model? (The BIZ model: A tool to enhance collaborative city governance and ensure effective service delivery and revitalization of the cities and regional economy: A case study of BIZ policy and governance networks in the Amsterdam Metropolis - Randstad region)
\end{abstract}

Keywords: Organization Adaptation. Public-Private Partnership. Governance network, Business Investment Zones, Policy network. 


\subsection{Introduction}

According to John Lim (2011), consensus government has always been the norm since the government's traditional top-down approach is increasingly becoming unproductive and unpopular. In the view of Kenis and Raab (2003), the government as the central actor has lost its credibility and faces constant criticism from stronger societal actors. This has made it difficult for most urban governments to implement policy decisions, especially in complex policy fields hierarchically. According to Abatecola (2015), the existing policy frameworks, with fragmented policy areas, are not suited for dealing with social complexity. Currently, policymakers and local government authorities in most cities are adopting best practices policies and develop managerial tools for sustainable urban governance. One such policy adaptation is using the business improvement districts (BIDs) city led management model. However, in the United States (U.S), where most of the BIDs originate, which has most of its citizens in the middle class, it is not uncommon to find inequalities in most of the cities (Osland,2013), and this has attracted academic interests (Zimmermann et al. 2008) as the effectiveness of the BIDs policy. This calls for the understanding of the new policy of the business investment zones (BIZ) as introduced in the Netherlands, the policy agents involved and their networks, and the BIZ's effectiveness as a policy tool to enhance effective service delivery and governance. Secondly, it is crucial to understand the various network structure signatures and how they could be utilized to inform and invigorate development in the broader region of Randstad.

\subsection{The Aim of the Study.}

This thesis aims to understand the business investment zone policy and governance network to understand why it was adopted and how it could be improved and implemented to bridge the gap between the traditional bureaucratic city management and the new collaborative city governance. This could produce relevant information and ideas which can be utilized in any governmental setting to resolve policy and management problems associated with organizational adaptation.

\subsection{The Results of the Study.}

This research could help identify the various (policy) network structure and their "key signatures" and how this relates to performance. This would serve as a "signature" or a guide of common nature to other networks in other regions. The signatures could foster to inform similar networks, and the actors involved, improve governance, sustain, and spread socioeconomic development and strengthen the network partnership to achieve a common policy goal.

\subsection{The Research Design, Methods and Data Collection}

The various questions in this study are dealt with in a multi-case study approach that incorporates policy and governance networks and the related processes within the various policy areas, involving different actors across. The rationale behind this research design is based on analytical generalizations that could provide a rich, contextualized understanding through intensive case studies. The research design is based on three independents but logically interrelated case studies, as shown in Figure 2.0. 


\section{|IMIIECONF}

4th International Conference On Research In

Figure 2.0 The Research Design

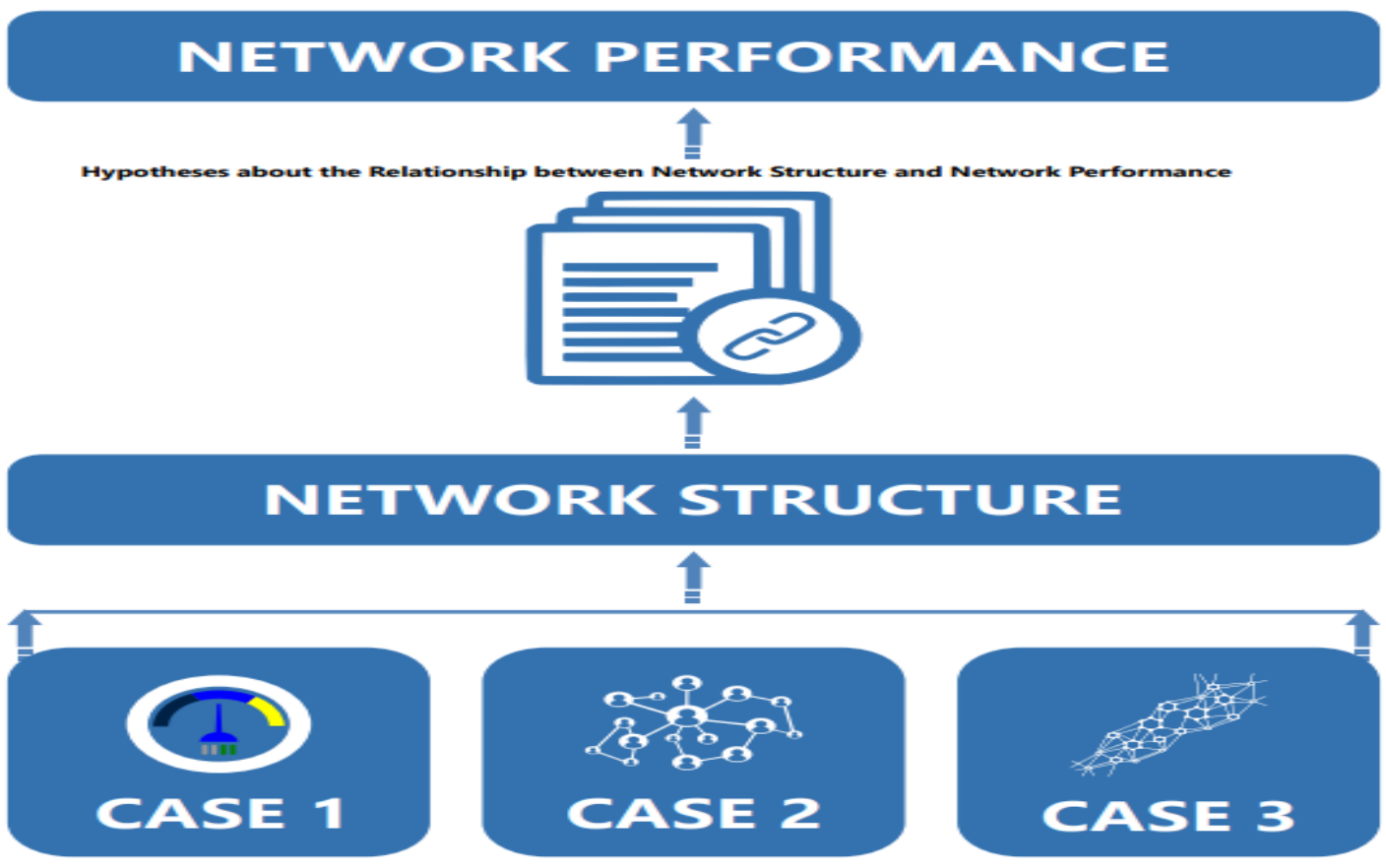

Source: Own

\subsection{Case Studies.}

2.1.1. Case Study I: Case study one involves some of the Identified networks within the municipal government in the Randstad, those concerned with creating new organizational units within the city management system, with organizational adaptation from the government to governance through a multilevel collaboration.

\subsubsection{Case Study II.}

The second case represents a policy process and a network of political and other actors working together with local entrepreneurs and the community to establish collaboration, fostering local economic, social, environmental development. The case study 2 represents a study of a policy network commonly referred to as a Triple Helix Network (THN).

\subsubsection{THE Case Study III}

The third case is a policy and governance networks entrusted with achieving collective action enhancing the adaptiveness of the local government management system. Case three involves the city management system. This case involves the co-management network. The comanagement here refers to the multi-actors with different sectors and hierarchies involved in the city management as well as the adaption process (Carlsson and Berkes, 2005; Olsson, Folke, and Berkes, 2004) 


\section{IIMIIECONF}

4th International Conference On Research In

\subsubsection{Common Features Of The Cases}

Notwithstanding the apparent differences, the cases here presented shares some resemblance. All the cases under examinations described above are a cross-boundary, multi actor-network in need of collaboration and joint action. Above all, all these networks are concerned with finding new answers to the problem through collective action or a joint problem-solving. Hence, the actors have resolved that no one actor on its own has the solution or the answers to their shared problem.

\subsection{Defining The Unit Of Analysis.}

The study investigates the relationship between the network structure and performance using a multi-case study design. The main issue here is how to identify and define the analytical units. As the study investigation relates to "bottom-up" policy rather than "top-down" policy. The thesis considers policy to be "a set of ideas and a practical search for institutional arrangements for their implementation" (Hjern 1997). The critical element here is the policy network and the implementation structures perceived as a problem-solving structure for shared solutions. Policymaking generally reflects the organizational processes that take place within the framework of collective networks. What this implies is that the various actors within the network collaborate to pursue their common interests (Bogdanor 1987, Rhodes, 1999). The term organization involves dividing tasks into different units and sharing tasks between different actors to be coordinated and carried out (Mintzberg 1979). Expressly, the various networks can be understood as the totality of the organizational arrangements and their organizing activities to find a solution to the problems identified.

Past studies have shown that, for analytical reasons, the policy process could be well-ordered and captured using a set of organizational functions; Thus, problem definition, prioritization, resource mobilization, and, finally, evaluation (Carlsson 1993; Hull and Hjern 1987; Rhodes,1999). While viewing the policy process as the totality of organizational functions, it is possible to map these policy networks and the actors involved empirically. The unit of analysis are defined, starting with the policy issues, however unlike a top-down approach which defines the actors as those who are formally linked to the authoritative implementation of a defined policy problem (Sabatier 1986). The bottom-up approach deviates from this perspective by focusing on policy networks' problem-solving capabilities (Carlsson 2000).

Using a multi-case study approach to investigate the research question makes this study divergent and multidisciplinary as shown in the various cases I to III. Consequently, the first case concerns organizational adaptation from the government to governance through multilevel collaboration. The second case concerns establishing a collaborative policy network to enrich and promote more robust regional economic development. The third case involves the achievement of collective action to improve the local government management system's adaptivity. In Cases, I and II, the analytical demarcation of policy processes is consistent with the authoritative policymakers' overall objective formulations. To further illustrate this, the policy networks in case I would be mapped according to who took part in creating new organizational units, a goal expressed in the local policy programme. Instead, a ground-based bottom-up would focus on networks that solve strategic problems, including, if possible, their relationship to the directions set out in the local policy programme. 


\section{IIMIIECONF}

4th International Conference On Research In

\subsection{Research Methods And Data Collection}

A case study methodology has been adopted, and data collection would be applied in all settings, although the various cases studied varied in some respects. The study seeks to map and analyze both policy network to identify their signatures to understand how this relates to performance. The analysis could reveal how the various actors are embedded and the discursive exchange tendencies among them that lead to policy initiative, implementation, evaluation, policy success, and or failure (De Leon,1999). The aim here is to adopt these network signature to shape other networks' development across a wider area (De Leon,1999).

\subsubsection{Method I: The Interview}

A case study approach has been adopted, and the most critical variables, are the network structure and performance, including the network signatures that are central to this thesis. Data for these variables would be collected using both qualitative and quantitative methods. The policy network is identified using the snowball sampling technique. This type of sampling is a non-probability method, which involves a random selection of subjects. This method is most effective, given the nature of the actors that are not easily accessible. The technique here is to inductively identify the population by allowing the actors to nominate each other (Miles and Huberman 1994). This approach according to Johnson (2003) involves a minimum of two stages: (a) the identification of a sample of respondents with characteristic $x$ at the zerostage $(s O)$; and (b) the solicitation of referrals to other potentially eligible respondents believed to have characteristic $x$ at snowball stages $s 1$ through $s k$. This referral process continues (or snowballs) until an acceptable number of eligible respondents have been located. Qualitatively, the research method aims to gain a deeper understanding of the phenomenon rather than generalize the findings (Goli et al.,2017) The phenomenological approach, in which the structure defines itself, elucidates the relevant actors involved in the policy process, regardless of formal hierarchies and organizational boundaries (Rhodes, 1999).

\subsubsection{Method II: Identifying the Network Signatures}

This part of the study uses an analytical framework from Deleon and Varda's Collaborative Policy Networks (2009) theory as a mechanism for rigorous empiric analysis. The proposed method would first seek to compartmentalize how "policy networks" are formed and the various qualities of such networks. These structural signatures are an identifiable "unique pattern" within which specific networks would be identified. The idea here is that there is a possibility that such signatures could be shaped for the creation of the network over time and be applied to different types of policy networks (De Leon, 1999). 


\section{IIMIIECONF}

4th International Conference On Research In

Figure 2.0: DeLeon and Varda's Theory of Collaborative Policy Networks

\begin{tabular}{|l|l|}
\hline Hypotheses & $\begin{array}{l}\text { Assumed Pattern in } \\
\text { Collaborative Policy Network }\end{array}$ \\
\hline $\begin{array}{l}\text { Hl: Diversity-Representing } \\
\text { different types of organizations } \\
\text { (Public, Private \& Non-profit) }\end{array}$ \\
\hline H2: Reciprocity/Reciprocal tie
\end{tabular}

Source: DeLeon and Varda (2009)

Figure (2.0) above represents DeLeon and Varda's hypotheses on collaborative policy networks. The first column shows the hypothesis; the second column indicates the type of relationships expected in collaborative policy networks. The third column points to the relationships found in traditional forms of bureaucratic government. Using the hypothesis illustrated in DeLeon and Varda's analytical model, this would be applied to the (BIZ)policy network in Amsterdam's metropolis to determine which of the statements or hypothesis is best supported by the sample data.

\subsubsection{Identifying the Structural Signature.}

The shift from bureaucratic agencies attending to public policy needs to the collective action of multi-agencies working in collaboration to solve complex public problems draws much attention. There is a need for theory that explains the emergence and evolution of such networks so that they may be modelled as examples of various policy issues (DeLeon and Varda,2002). This part of the study uses an analytical framework from Deleon and Varda's Collaborative Policy Networks (2009), a theory as a mechanism for rigorous empiric analysis. The proposed method would first seek to compartmentalize how "policy networks" are formed and the various characteristics identifiable with such networks. These structural signatures are an identifiable "unique pattern" within which specific networks would be identified. The idea here is that there could be a possibility that such qualities could be shaped for the development of the network over time and be applied to different types of policy networks (De Leon, 1999). 


\section{IIMIIICONF}

4th International Conference On Research In

This part of the study would help to give credence the link between network structure and performance. To develop an analytical framework, several measures will be operationalized to be analyzed both descriptively and empirically. This study proposes implementing a set of network measures to test which structural trends are most likely to occur (Monge \& Contractor, 2003). The list of hypotheses (1-5 in the diagram) is a set of a proposed collaborative policy network, and their structural signatures would be operationalized. Based on this hypothesis, the study would be identifying the probability that a specific characteristic has occurred. Identification of the probability of a structural signature occurring in a network structure requires the use of social network analysis (SNA). The understanding gained could lead to a better understanding of collaborative city governance in the Randstad. Secondly, this could lead to a new analytical insight into the world of public policy development and implementation.

\subsection{Network Structure and Network Performance}

According to Burt (2000) better-connected individuals and organizations tend to perform better, and therefore is very essential to determine what it means to be better connected. Various studies have emphasized network closure and structural holes as the divergent structure underlying such an advantageous location in a social network (Zhang et al., 2015). The cohesive social ties lead to trust and collaboration, whiles a central location in a social network leads to more bonding relationships (Coleman, 1988, 1990). The basic proposition is that closure facilitates the interactions because of an enhanced communication among the participators. Therefore, any organization embedded in this type of structure is regarded as rich in social capital. Networks with high levels of network closure have more social capital and are, accordingly, more successful in achieving collective action than others. Network with structural holes as suggested by (Burt, 1997) shows that social capital results from information control and brokerage opportunities available for organizations who hold a network bridge that spans otherwise disconnected groups. Thus, the very existence of holes provides specific opportunities for actors who are successful in taking advantage of these to enjoy the benefit of brokering information among actors on each side of them. The fundamental idea of structural hole theory is that people who constitute bridges between structural holes are rich in social capital because they can access new and more diversified sets of resources. Accordingly, networks comprised of such individuals are considered rich in social capital, rich in opportunities, and better performing (Burt,2000).

\subsection{The Combined Effects of Network Closure and Structural Holes}

The combined approach acknowledges the ideas of both network closure and structural holes as essential qualities for performance, although by fulfilling different functions in network collaboration. However, for analytical clarity, there is the need to clarify the localized and international structures of policy networks. The localized structure indicates the in-group activities of the network, whereas the international structure points to how the network is connected to other network constellations. The low level of interaction among those involved in the network with structural holes, according to Burt (2001), does not encourage any form of institutionalization process. The underlying logic is that "while brokerage across structural holes seems to be the source of added value, closure can be critical to realizing the value buried in the structural hole" (Burt 2000). 


\subsubsection{Network Performance: Effectiveness And Efficiency.}

Network performance, which refers to the outcome of the networking activities, considers both the indented and unintended results of the process. Based on the understanding of policy networks as problem-solving entities, performance will be evaluated due to organizing capacities and dealing with these problems.

Effectiveness connotes many meanings (Abrahamsson 1993; Vedung 1997). In this study, effectiveness (external effectiveness) will be recognized as the ability to reach the organizational objectives around which the networks have been formed. This quality is distinguished from the term efficiency (internal effectiveness), which is more concerned with the internal organizing process and the relation between performance and the costs for performing, pointing to the effort and resources required to produce the desired results (Abrahamsson 1993).

\subsubsection{Effectiveness}

The effectiveness of the business investment zone (BIZ) policy processes is examined by asking questions about the level of goal attainment. In this study, the effectiveness of the policy networks is evaluated based on their problem-solving capacities by addressing the overall goal fulfilment.

In case I, establishing a new and innovative management model by creating new organizational units within the city management system, with organizational adaptation from the government to governance through a multilevel collaboration, would be considered an indicator of this quality.

In Case II, effectiveness is indicated by identifying and bringing together a network of political and other actors working together with local entrepreneurs and the community to establish collaboration, fostering local economic, social, environmental development has been realized or not.

Case III involves establishing a policy and governance networks entrusted with achieving collective action, enhancing the adaptiveness of the local government management system. Thus, a network for co-management refers to multi-actors with different sectors and hierarchies involved in city management. More specific questions asked in each case to connect the empirical material to the idea of effectiveness.

\subsubsection{Efficiency}

The complexity of actors, interests, and goals present in policy settings is a recurring theme of this thesis. The bargaining character of the processes implies that goals are not easily set; indeed, they are constantly being negotiated. The actors' ability to modify their own goals and weigh their purposes against others is an essential feature of a well-functioning policy process. The ability to reach consensus, especially on a specific directive or particular action to be taken and how among those involved, is referred to as a "covenanting capacity" of networks. In this thesis, this capacity is captured by the term efficiency, referring to the internal processes clarified by asking the respondents about the work, time, and resources needed to reach their ambitions. In other words, efficiency is believed to capture the capacity for collective action.

\subsection{SUMMARY}

Undoubtedly, the notions of effectiveness and efficiency are closely intertwined. Still, while the former assigns the qualitative aspects of collective action, the latter is about its very existence. Regarding the top-down/bottom-up discussion as applied in this study; one could 
perhaps propose that the understanding of efficiency applied in this thesis is more related to the bottom-up methodology. At the same time, the notion of effectiveness draws on a more top-down perspective as it addresses overall goal fulfilment. A structure might be efficient but not effective or practical; however, it is unlikely to find situations when it is the other way around. "A certain degree of efficiency is a necessary but not sufficient condition for effectiveness" (Abrahamsson 1993).

\subsection{Network Closure.}

A network characterized by closure is a well-connected network, either directly by many strong connections or indirectly through a common, coordinating contact. While the former refers to the level of activity within the network, the latter designates hierarchy (Burt 2000). In this thesis, network closure will be empirically identified by applying two network measures: density and centralization.

\subsubsection{Network Density}

Network density is perhaps the most basic and probably also the most recurring concept used within the branch of social network analysis (SNA). Most often, it is associated with a general notion of network cohesion. The denser the network is, the higher the level of closure is assumed, enhancing all the beneficial elements, such as improved internal collaboration.

\subsubsection{Centralization}

The level of the hierarchy, empirically measured by network centralization, is the second indicator of network closure. When a network is highly centralized, significant variations occur regarding the activity level among the involved, such as those illustrated by a robust coordinating unit. As such, a high level of the hierarchy is assumed, which is interpreted as a structure characterized by a high degree of network closure (Burt 2000). Whereas density reflects the proportion of ties present, centralization reflects their configuration, providing information regarding the extent to which the activities are dependent upon one dominant individual.

\subsection{THE General Hypothesis}

H1. The network structure matters for policy making within policy networks and affects performance. More specifically,

H2. Two central network qualities - namely, network closure and the existence of global structural holes-influence performance.

Although structural holes are potential sources of resources, network closure is critical for the use of the resources obtained.

Consequently, H3. A high performing network is a network with a local structure, characterized by a high level of closure, that spans structural holes in the global structure.

H4. The network structure matters for policymaking within policy networks and affects their efficiency and success.

H5. Two central network qualities, namely network closure and network heterogeneity, affect performance in terms of their efficiency and effectiveness.

H6. A high performing policy network is a heterogeneous network with a high level of network closure. 


\subsection{THE Methods Of Analysis}

The network-level characteristics would be determined, compared across networks. This would be used to answer questions such as how the network's overall production capacity could be enhanced and how multiorganizational services provided to a region could be strengthened. This perspective presumes that a network involves many organizations collaboratively working toward a common goal (Schalk, Torenvlied, \& Allen, 2010).

Therefore, one network organization's success or failure may or may not necessarily be translated as the success or failure of the entire network and another or the group, area, city, or region.

This study has adopted social network analysis (SNA) method based on two properties of centrality and embeddedness and resource dependency theory (RDT). Being a central node in the network, with many links and good connections to the rest of the actors, is correlated with being assertive and significant (Faust \& Wasserman, 1992; Moreno, 1934). This also implies having the ability to spread ideas (Banerjee, Chandrasekhar, Duflo, \& Jackson, 2013), good access to resources, and the capacity to intermediate and orchestrate actions carried out by other actors (Freeman, 1978). On the other hand, embedded in a densely connected cluster implies belonging to a group of actors with standard rules, mutual control, and trust, maintaining frequent interactions and reciprocal information flows among them (Granovetter, 1985; Uzzi \& Spiro, 2005). These characteristics exhibited by actors can boost network performance (Schalk, Torenvlied, \& Allen, 2010). In a network relationship, popular organizations are more desirable to partner with than others, with higher networking opportunities (Berardo \& Scholz, 2010).

\subsubsection{Preliminary Findings.}

This thesis examines policy networks concerned with the implementation of a BIZ policy program within the Amsterdam Metropolis. This includes identified processes and related policy networks to develop innovative management within public organizations to enhance network performance and collaborative governance. The variations in the performance have looked at from network perspectives. Several questions guided the investigation, however few of these which stands out most are.

1. Does a relationship exist among the policy networks' network structure, their organizing capabilities, and their performance in terms of productivity and value?

2. Do other relationships exist between network structure and network performance that ought to be recognized?

Based on the empirical analysis, these questions could be positively answered. The empirical analysis points to the preliminary conclusion that network structure does matter for the organizing capacities and the policy networks' performances. The empirical data also reveal a positive relation between value (Quality) and the level of network heterogeneity. Consequently, a high performing network is a network in which the actors are tightly connected and simultaneously have many connections to other actors engaged in other constellations.

\subsection{Limitations And Conclussion}

There is an issue with the operationalization of the dependent and independent variables and their relationship. Even though the analytical design treats network structure as the independent variable and performance as the dependent variable, it must point out that this relationship, in 
some respects, can be reversed. This thesis has shown that it is imperative to develop the standpoint that networks do matter for policymaking performance and, therefore, need to be treated seriously. The network structure is an important variable to consider since it says something about the organizing capacities of policy networks and what could be achieved within these structures.

\section{References.}

Abatecola, G. (2019). Organization and Management Theory. Division Oraganizational Adaptation and Survival; Literature Review. 72 Annual Meeting of the Academy of Management . Boston: Academy of Management.

Bogatti, S., Jones, C., \& and Hesterly, W. (1997). A General Theory of Network Governance: Exchange Conditions and Social Mechanisms. The academy of management review, 22(4), 911-945.

Burt, R. (2000). The Network Structure of Social Capital. Research in Organizational Behaviour. Greenwich: JAI Press.

Cameron, K. (1984). Organizational Adaptation and Higher Education. The Jounal of Higher Education, 55(2), 122-144.

Davis, S. (1997). Business Improvement Districts. Jounal of urban and contemporary law, 51(15), 187223.

Dolowitz, D., \& David, P. (2009). Learning by observing: surveying the international arena. Policy and Politics, 37(3), 317-334.

Davis, S. (1997). Business Improvement Districts. Jounal of urban and contemporary law, 51(15), 187223.

Dolowitz, D., \& Mash, D. (2000). Learning from Abroad: The Role of Policy Transfer in Contemporary Policy- Making. An International journal of Policy, Administration and Institution, 13(1), 5-23.

Ebrahimi, P., Ebrahimi, C., \& MoosaviS, M. (2016). Relationship between Leadership Styles and Organizational Performance by Considering Innovation in ManufacturingCompanies of Guilan Province. (pp. 351-358). Dubai: Elsevier.

Evans, M. (2017). Policy Transfer in Global Perspective. New York: Routledge.

Granovetter, M. (1992). Economic Institutions as a Social Constructions. Policies studies Journal, 502520.

Gray, D., \& Tam, S. (2016). What Can We Learn from the Organizational Life Cycle Theory?A Conceptualization for the practice of work place learning. Journal of Management Research, 2(8), 1-13.

Hjern, B. (1987). Policy Analysis: An Implementation Approch. Chicago: American Policy Science association.

Howlett, M., \& Lejano, R. (2013). The Rise and Fall (and Rebirth?) of Policy Design. Sage, 45(3), 357381. 
Kenis, P., \& Raab, J. (2003). Wanted: A Good Network Theory of Policy Making. washington DC: Department of Policy and Organization Studies .

Klijn, E., \& Koppenjan, J. (2016). The impact of contract characteristics on the performance of publicprivate partnerships. Public Money and Management, 36(6), 455-462.

Marsh, D., \& Smith, M. (2000). Understanding Policy Network: Towards a Dialectical Approach . Political Studies, 4-21.

Morçöl, G., \& Zimmermann. (2006). Metropolitan Governance and Business Improvement Districts. International Journal of Public Administration, 29(1-3), 5-29.

North, D. (1990). Institutions, Institutional Changes and Economic Performance. Cambridge: Cambridge University Press.

OECD. (2013). Corporate Governance Better Policies for Board Nomination and Election in Asia. OECD.

Olsson, P., Folke, F., \& Berkes, F. (2004). Adaptive Co-Management for Building Resilience in Social Ecological Systems. Journal of Environmental Management, 63-72.

Osland, J. (2003). Broadening the Debate: The Pros and Cons of Globalization. Journal of management enquiry, 12(2), 137-154.

Oxborne, D., \& Gaebler, T. (1992). Reinvesnting Government (Vol. 27). New York: Penguin Press.

Prince, R. (2016). Neoliberalism Everywhere: Mobile Neoliberal Policy. In Handbook of Neoliberalism (pp. 331-339). London: Routledge.

Raab, C. (2001). Understanding Policy Network: Comment on Mash and Smith. Political Studies, 551556.

Springer, S., Birch, K., \& Macleavy, J. (2016). An Introduction to Neoliberalism. Retrieved 0803 , 2020, from www.Researchgate.net

Kenis, P., \& Raab, J. (2003). Wanted: A Good Network Theory of Policy Making. washington DC: Department of Policy and Organization Studies .

Klijn, E., \& Koppenjan, J. (2016). The impact of contract characteristics on the performance of publicprivate partnerships. Public Money and Management, 36(6), 455-462.

Kotz, D. (2002). Globalization and Neoliberalism . Rethinking Marxism, 12(2), 64-79.

Marsh, D., \& Smith, M. (2000). Understanding Policy Network: Towards a Dialectical Approach . Political Studies, 4-21.

Monbiot, G. (2016, April 15). BST. Retrieved July 29, 2020, from www.theguardian.co.uk

Morçöl, G., \& Zimmermann. (2006). Metropolitan Governance and Business Improvement Districts. International Journal of Public Administration, 29(1-3), 5-29.

North, D. (1990). Institutions, Institutional Changes and Economic Performance. Cambridge: Cambridge University Press.

OECD. (2013). Corporate Governance Better Policies for Board Nomination and Election in Asia. OECD. 
Olsson, P., Folke, F., \& Berkes, F. (2004). Adaptive Co-Management for Building Resilience in Social Ecological Systems. Journal of Environmental Management, 63-72.

Osland, J. (2003). Broadening the Debate: The Pros and Cons of Globalization. Journal of management enquiry, 12(2), 137-154.

Oxborne, D., \& Gaebler, T. (1992). Reinvesnting Government (Vol. 27). New York: Penguin Press.

Prince, R. (2016). Neoliberalism Everywhere: Mobile Neoliberal Policy. In Handbook of Neoliberalism (pp. 331-339). London: Routledge.

Raab, C. (2001). Understanding Policy Network: Comment on Mash and Smith. Political Studies, 551556.

Rogers, E., \& Shoemaker, F. F. (1971). Communication of Innovations; A Cross-Cultural Approach. New York: The Free Press.

Springer, S., Birch, K., \& Macleavy, J. (2016). An Introduction to Neoliberalism. Retrieved 0803 , 2020, from www.Researchgate.net

Williamson., O. (1991). Economic Institutions: Spontaneous and Intentional Governance. ournal of Law, Economics, \& Organization, 7, 159-187.

Wood, D., \& Gray, B. (1991). Toward a Comprehensive Theory of Collaboration. Sage, 27(2), 139162.

Wood, D., \& Gray, B. (1991). Toward a Comprehensive Theory of Collaboration. Sage, 27(2), 139162.

Yin, R. (1994). Case Study Research, Design and Methods. ST: Sage. 